\title{
The relationship between the bone characters obtained by $C B C T$ and primary stability of the implants
}

\author{
Masahiro Wada*, Yasutane Tsuiki, Tohru Suganami, Kazunori Ikebe, Motofumi Sogo, Ikuhisa Okuno
} and Yoshinobu Maeda

\begin{abstract}
Background: The aim of this study is to investigate the correlation between the thickness of the cortical bone or the voxel values that are obtained by cone beam $C T$ (CBCT) and the insertion torque values (ITVs) or the implant stability quotient (ISQ) values.

Methods: A pig's ilium was used as the implant placement site. The implants used in this study were two kinds of diameters $(3.8 \mathrm{~mm}, 5.0 \mathrm{~mm})$ and two kinds of lengths $(7.0 \mathrm{~mm}, 12.0 \mathrm{~mm})$ having a general threadlike shape with a mechanically polished surface. To measure the bone density and the cortical thickness around the implants accurately, the CBCT scanning was performed immediately just after the formation of the implant cavity. The initial stabilities were evaluated by the ITVs and the ISQ values. The bone density and cortical thickness around the implants were measured by an implant simulation software (Landmarker ver. 5.0 with special specifications for this study). The relationships of the thickness of the cortical bone and the voxel values with the ITVs and the ISQ values were analyzed using Pearson's correlation coefficient. To evaluate the influence on the ITVs and the ISQ values among multiple factors, multiple regression analysis was performed. $P<0.05$ was considered statistically significant.

Results: A significant positive correlation was found between the thickness of the cortical bone and the ITVs or the ISQ values in all kinds of implants. In addition, a significant positive correlation was also found between the voxel values and the ITVs. From the multiple regression analysis, the thickness of the cortical bone and the voxel values had a positive influence on the ITVs and the ISQ values. In addition, the length of the implant had a positive influence on the ISQ values at the 3.8-mm-diameter implant.

Conclusions: In this limited study, there were correlations between the thickness of the cortical bone or the voxel values obtained from the CBCT scanning and the implant stabilities. Besides, it was confirmed that the thickness of the cortical bone, the voxel value, and the implant length had positive correlations with the ITVs and the ISQ values.
\end{abstract}

Keywords: Primary stability; CBCT; Voxel value

\section{Background}

The primary stability of an implant at the time of placement is considered as one of the key factors for clinical success of implant treatment [1-6]. Orenstein et al. reported that implants that were appropriately stabilized without any mobility at the time of placement had a significantly high survival rate compared with those that were not [7].

The evaluation of the primary implant stability is usually

\footnotetext{
* Correspondence: masahiro@dent.osaka-u.ac.jp

Department of Prosthodontics, Gerodontology and Oral Rehabilitation, Osaka University Graduate School of Dentistry, 1-8 Yamadaoka, Suita, Osaka 565-0871, Japan
}

\section{Springer}

(c) 2015 Wada et al.; licensee Springer. This is an Open Access article distributed under the terms of the Creative Commons Attribution License (http://creativecommons.org/licenses/by/4.0), which permits unrestricted use, distribution, and reproduction in any medium, provided the original work is properly credited. performed after placement. Some of the main methods include mobility test, resonance frequency analysis, and the measurements of the removal torque values and the insertion torque values (ITVs). In particular, the measurement of the removal torque values is an objective evaluation method, but its clinical application is difficult because it is an irreversible and invasive method. Mobility test is useful for the evaluation of an implant whose osseointegration was surely obtained, but there is a possibility that the primary stability could decrease by the impact of the tapping head. On the other 
hand, the measurement of ITVs and the measurement of implant stability quotient (ISQ) values by using a resonance frequency analyzer are non-invasive, convenient, and objective evaluation methods. Therefore, these methods are used for evaluation in various researches investigating the primary stability including immediate loading implants [8-11].

The primary stability is significantly affected by bone quality. Herrmann conducted a study of the prognosis for as long as more than 5 years and reported that poor bone quality and quantity had a major impact on the long-term failure rate of implants [12]. Jaffin observed the prognosis of implants for 5 years after providing the final restoration [13]. As a result, the failure rate of the implants was $3 \%$ when the implant was placed in the alveolar bone having a thick cortical bone or otherwise a dense spongy bone even if the cortical bone was thin, whereas it was $35 \%$ when the implant was placed in the alveolar bone having both a thin cortical bone and a sparse spongy bone.

Some of the methods to evaluate the bone quality that influences the primary implant stability have already been applied in a clinical practice. Lekholm and Zarb classified bone density into four types in terms of radiography, with the thickness of the cortical bone and the density of the spongy bone as the indexes [14]. This classification method is accepted most commonly at present but is problematic with accuracy and reproducibility because it is a subjective evaluation. On the other hand, Misch classified CT values (Hounsfield unit) into five steps (D1: >1,250 HU; D2: 850 to 1,250 HU; D3: 350 to 850 HU; D4: 150 to $350 \mathrm{HU}$; D5: <150 HU) to evaluate the bone quality [15]. The CT value is the value obtained by multi-detector CT (MDCT) and is defined as the relative value of the X-ray attenuation coefficient of the object for water, with the $\mathrm{X}$-ray attenuation by water defined as zero. Today, this classification has been used for the evaluation of the bone quality because it is an objective method compared with that of Lekholm and Zarb.

Turkyilmaz et al. placed 24 implants in human dry bones and calculated CT values using MDCT images before surgery to examine correlations with the ITVs and the ISQ values [16]. They reported that there were significant correlations of CT values with both ITVs and ISQ values and that bone density (CT value) was one of the factors that had an influence on the primary implant stability.

In recent years, cone beam $\mathrm{CT}(\mathrm{CBCT})$ has been used for preoperative diagnosis in implant treatment. $\mathrm{CBCT}$ is superior for its high definition, reduction of the exposure dose, low cost, and usability compared with MDCT [17-21]. However, CBCT does not have a linear relationship compared with the CT values obtained by MDCT, and therefore, it is considered difficult to evaluate bone density quantitatively [22-24]. The major causes arise from the lack of calibration of X-rays, the localized imaging area that allows various external anatomical structures, and too many scattered radiations.

It is therefore considered that MDCT is appropriate for the precise evaluation of bone density. However, since the use of $\mathrm{CBCT}$ is spreading rapidly among general practitioners, it is clinically of great significance to predict the primary stability after implant placement using the information obtained by CВCT. In addition, in late years, $\mathrm{CBCT}$ or the calibration software which can convert the voxel values into CT values is developed.

We therefore investigated in this study the correlation between the thickness of the cortical bone or the voxel values that are obtained by CBCT and the ITVs or the ISQ values.

\section{Methods}

Bone models

A flat part of a pig's ilium was used as the implant placement site to secure as vertical implant placement and an equal depth of insertion to the bone surface as possible (Figure 1).

\section{CBCT scan}

GXCB-500 (GENDEX, Des Plaines, IL, USA) was used as the $\mathrm{CBCT}$ device to obtain almost identical voxel values to the $\mathrm{CT}$ values that could be obtained from MDCT. Scanning conditions were as follows: the tube current, $5 \mathrm{~mA}$; the tube voltage, $120 \mathrm{kV}$; the field of view (FOV), 85-mm diameter to secure a complete size for

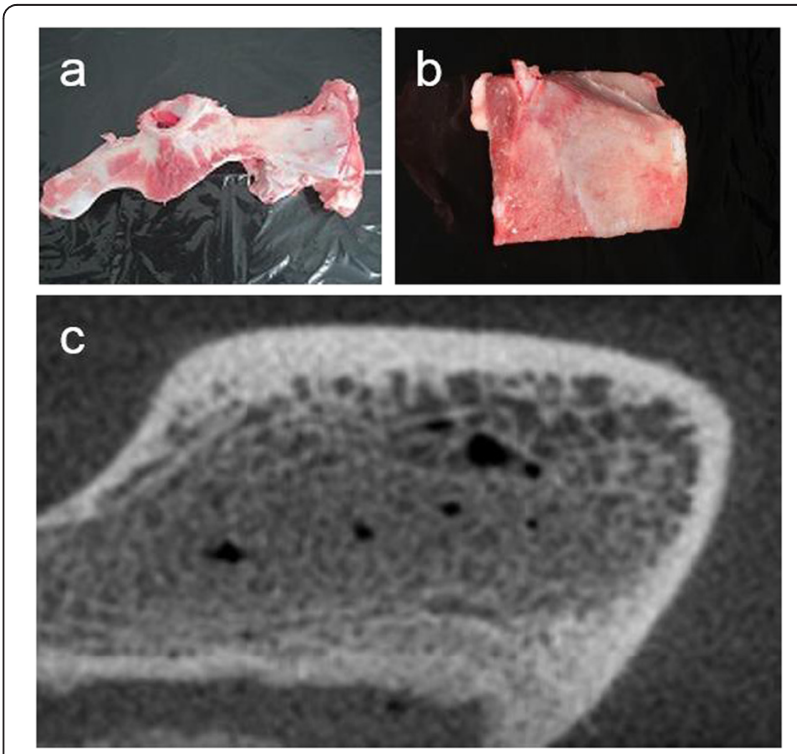

Figure 1 The bone model in this study (a pig's ilium). (a) The whole picture of the ilium. (b) The flat part of the posterior margin of the ilium. (c) The $\subset T$ image of the ilium. 
scanning; and the voxel size, $0.1 \mathrm{~mm}^{3}$. In addition, the scanning was performed by immersing the samples in a polypropylene container with water in it to create as similar scanning environment as possible to the one that had soft tissues around the bone model. Of note, the scanning was performed immediately just after the formation of the implant cavity to accurately measure the voxel values around the inserted implants.

\section{Implants}

External Hex Implants for laboratory use $\left(\mathrm{SETiO}^{\circ}, \mathrm{GC}\right.$ Company, Tokyo, Japan) having a general threadlike shape with a mechanically polished surface were used. They were two kinds of diameters $(3.8 \mathrm{~mm}, 5.0 \mathrm{~mm})$ and two kinds of lengths $(7.0 \mathrm{~mm}, 12.0 \mathrm{~mm})$ consisting a total of four groups, and 25 pieces of implants were used in each group (Figure 2).

\section{Formation of the implant cavities}

When forming an implant cavity, it is necessary to move the drill back and forth along the insertion direction. This process is usually done by an operator with freehand, but it is likely to cause unevenness in the diameter of the implant cavity. Therefore, an implant cavity-forming device was used to prevent this in our experiment (Figure 3). This device is able to adjust the up-and-down movement speed and the rotation speed of the drill. In this study, the implant cavity was constructed at a moving speed of $5 \mathrm{~mm} / \mathrm{s}$ that was close to the actual up-and-down movement speed obtained from the preliminary experiment and at $800 \mathrm{rpm}$ according to the manufacturer's protocol. It was also confirmed in the preliminary experiment that using this device would significantly reduce the unevenness of the diameter of the implant cavity.

All the procedures of forming an implant cavity were unified as follows according to protocols. Firstly, the implant cavity was constructed by using a 2.0 -mm-depth drill after marking the implant site using a guide drill. Secondly, a $3.1-\mathrm{mm}$ pilot drill and a $3.1-\mathrm{mm}$ twist drill

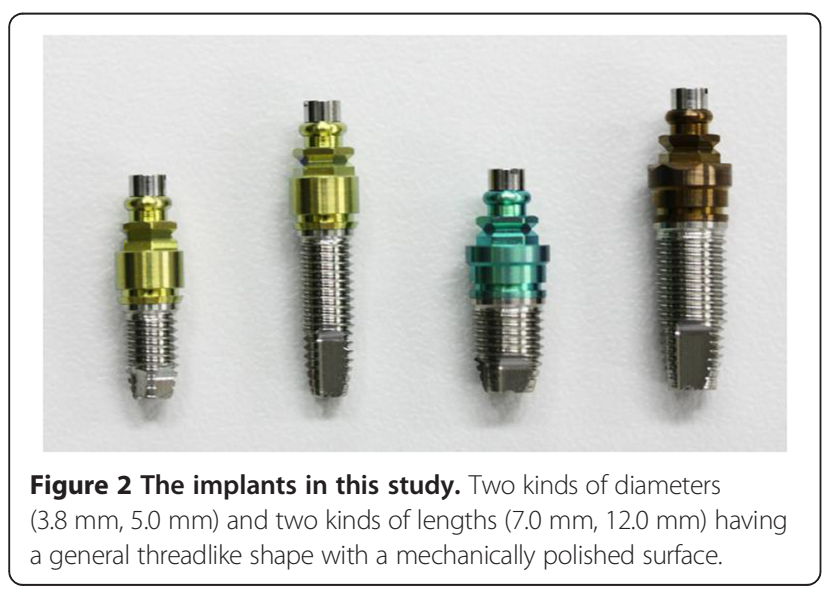

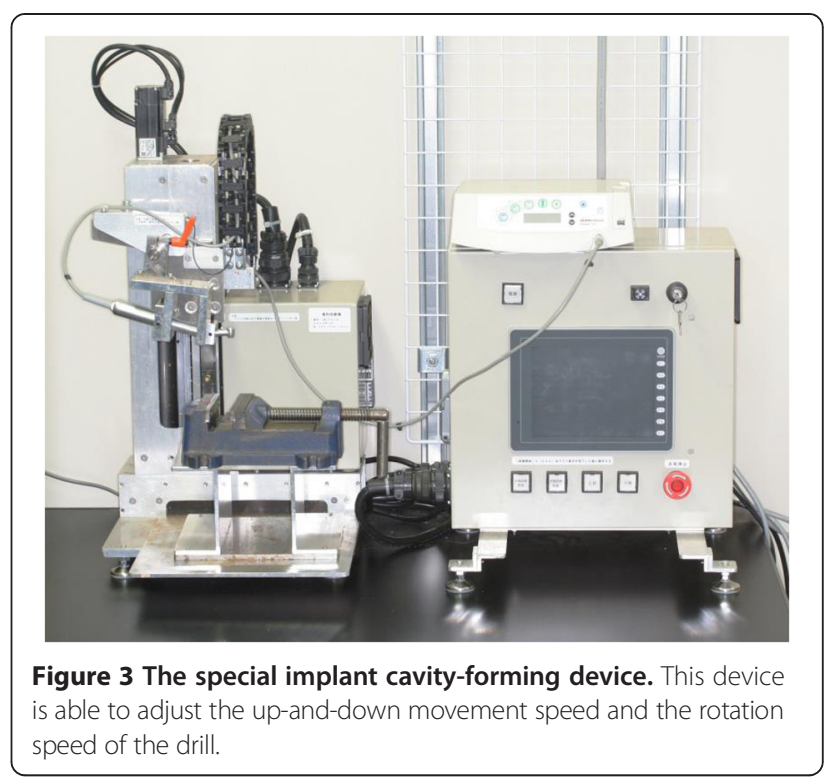

were used to form a cavity for an implant with $3.8-\mathrm{mm}$ diameter, and a $4.3-\mathrm{mm}$ pilot drill and a $4.3-\mathrm{mm}$ twist drill were used to form a cavity for an implant with 5.0$\mathrm{mm}$ diameter. Of note, this experiment was performed under a non-irrigation environment because the rise of temperature would not be problematic.

\section{Placement of an implant and the measurement of the implant stabilities}

Handy Type Torque Meter (HTG2-200NC, IMADA-SS Corp, Aichi, Japan) was used for the placement of an implant, and the maximum torque values were measured. The specifications of the Handy Type Torque Meter were as follows: the measurement unit, $\mathrm{Ncm}$; the accuracy, within $\pm 0.5 \% \mathrm{FS}$; the measurement maximum torque, $200 \mathrm{Ncm}$; and the minimum resolution function, 0.1 $\mathrm{Ncm}$. Thus, the device had enough coverage of the torque measurement in this study ( $96.0 \mathrm{Ncm}$ at maximum).

Osstell Mentor (Integration Diagnostics AB, Gôteborg, Sweden) was used as a resonance frequency analysis device to measure the ISQ values. The accompanying smart peg (type 1) was attached to the implant for the measurement at every $90^{\circ}$, and the average value was calculated.

\section{Measurement of the voxel values and the thickness of the cortical bone around implants}

An implant simulation software (Landmarker ver. 5.0 with special specifications for study purposes, iCAT, Osaka, Japan) was used for analysis. The evaluation site was selected on the smallest area that was as adjacent to the implant as possible so as not to include the area that was immune to the primary stability. Specifically, the width of the measurement site was defined as $0.50 \mathrm{~mm}$, i.e., from $0.25 \mathrm{~mm}$ inside (the to-be-compressed area at 
the time of placement) to $0.25 \mathrm{~mm}$ outside of the virtual implant. The area adjacent to the bottom of the implant was excluded from the measurement site because the maximum torque value and the ISQ value were both subject to the lateral force a great deal (Figures 4 and 5). Then, the voxel values of the measurement site were extracted into the comma-separated values (CSV) files. Subsequently, the average of the voxel values of the measurement site was calculated and defined as the voxel value of the whole bone around the implant. Additionally, the average of the voxel values was calculated at every $0.1-\mathrm{mm}$ depth from the surface of the bone to determine the thickness of the cortical bone from the voxel values. The threshold of the voxel value for the border of the cortical bone and the spongy bone was decided to be 350, which had a strong correlation (Pearson's correlation coefficient, 0.897) with the actual measurement in the preliminary examination.

\section{Statistical analysis}

The relationships of the thickness of the cortical bone and the voxel values with the ITVs and the ISQ values were analyzed using Pearson's correlation coefficient. Then, multiple regression analysis was performed using the ITVs or the ISQ values as the dependent variable and using the thickness of the cortical bone, the voxel value, and the length of the implant as the independent variables to evaluate the influence on the ITVs and the ISQ values among multiple factors. The statistical analyses were performed using the SPSS ver. 22 software

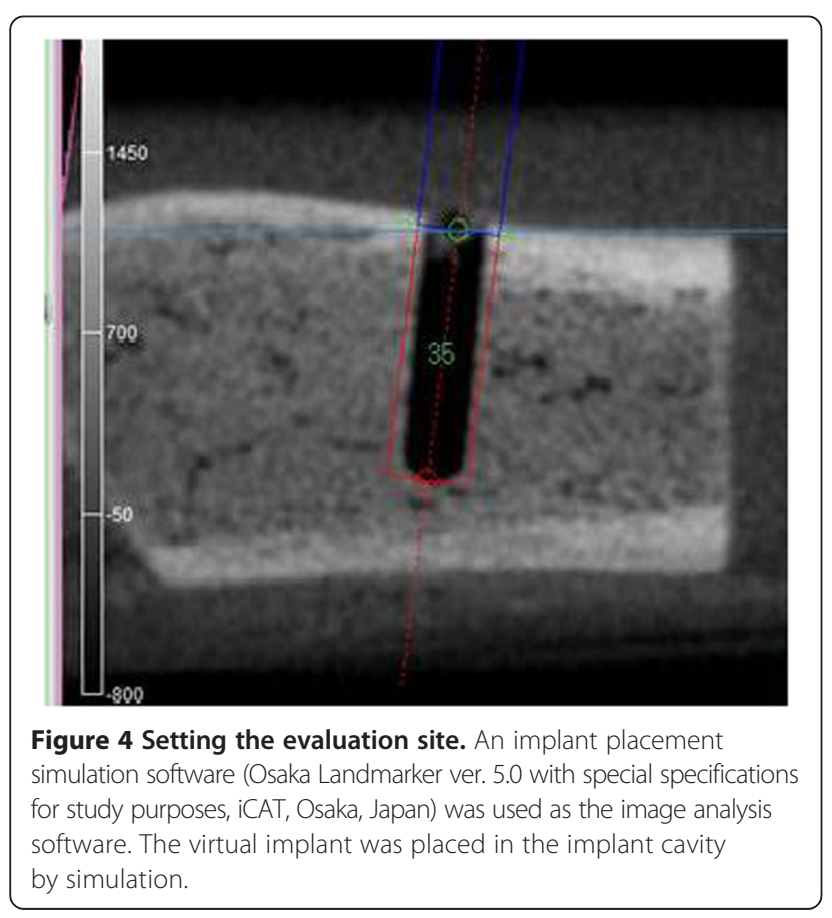

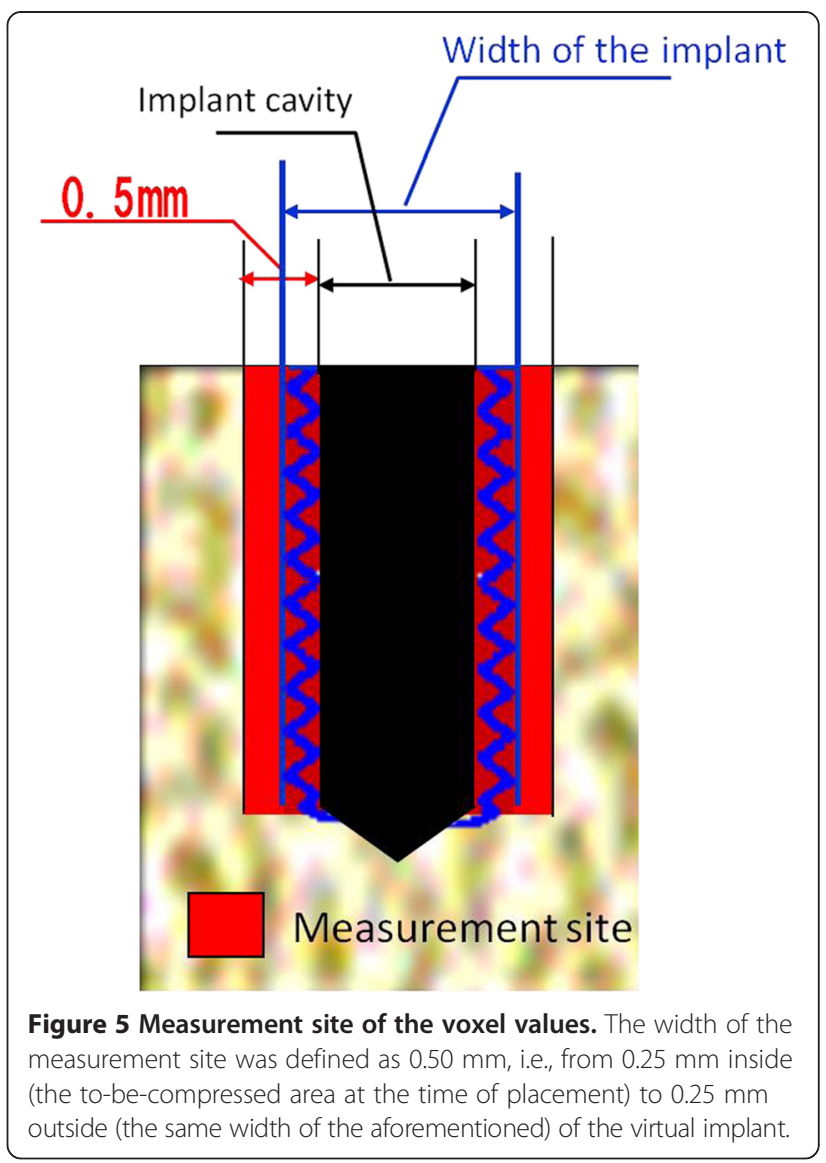

(SPSS Co., Chicago, IL, USA). $P<0.05$ was considered statistically significant.

\section{Results}

Relationship between the thickness of the cortical bone and voxel values with implant stabilities

A significant positive correlation was found between the thickness of the cortical bone and ITVs or ISQ values in all kinds of implants. In addition, a significant positive correlation was also found between the voxel values and ITVs. On the other hand, in the relationship between the voxel values and ISQ values, we cannot confirm a correlation of the implant of $5.0 \mathrm{~mm}$ in width and $12.0 \mathrm{~mm}$ in length (Table 1).

\section{Influence of the implant of $3.8 \mathrm{~mm}$ in width on the ITVs and the ISQ values of each factor}

Multiple regression analysis was performed using the ITVs or the ISQ values as the dependent variable and using the thickness of the cortical bone, the voxel value, and the length of the implant as the independent variables. The standardized partial regression coefficients of the thickness of the cortical bone and the voxel value were 0.400 and 0.459 , respectively, which turned out to be significant explanatory variables. However, that of the 
Table 1 Correlation between bone factors and stability factors

\begin{tabular}{|c|c|c|c|c|c|}
\hline Bone factors/stability factors & Diameter $(\mathrm{mm})$ & Length $(\mathrm{mm})$ & $r$ & $P$ & $n$ \\
\hline \multirow[t]{4}{*}{ Thickness of the cortical bone/ITVs } & 3.8 & 7 & $0.744^{* *}$ & $<0.001$ & 24 \\
\hline & & 12 & $0.560^{* *}$ & 0.005 & 23 \\
\hline & 5 & 7 & $0.815^{* *}$ & $<0.001$ & 25 \\
\hline & & 12 & $0.760^{* *}$ & $<0.001$ & 24 \\
\hline \multirow[t]{4}{*}{ Thickness of the cortical bone/ISQ } & 3.8 & 7 & $0.831^{* *}$ & $<0.001$ & 24 \\
\hline & & 12 & 0.409 & 0.052 & 23 \\
\hline & 5 & 7 & $0.707^{* *}$ & $<0.001$ & 25 \\
\hline & & 12 & $0.426^{*}$ & 0.038 & 24 \\
\hline \multirow[t]{4}{*}{ Voxel values/ITVs } & 3.8 & 7 & $0.601^{* *}$ & 0.002 & 24 \\
\hline & & 12 & $0.745^{* *}$ & $<0.001$ & 23 \\
\hline & 5 & 7 & $0.850^{* *}$ & $<0.001$ & 25 \\
\hline & & 12 & $0.667^{* *}$ & $<0.001$ & 24 \\
\hline \multirow[t]{4}{*}{ Voxel values/ISQ } & 3.8 & 7 & $0.684^{* *}$ & $<0.001$ & 24 \\
\hline & & 12 & $0.447^{*}$ & 0.032 & 23 \\
\hline & 5 & 7 & $0.695^{* *}$ & $<0.001$ & 25 \\
\hline & & 12 & 0.270 & 0.202 & 24 \\
\hline
\end{tabular}

ITVs, insertion torque values. ${ }^{* *} P<0.01 ;{ }^{*} P<0.05$.

length of the implant did not become an explanatory variable. When using the ISQ values as the independent variable, the standardized partial regression coefficients of the thickness of the cortical bone, the voxel value, and the length of the implant were 0.326, 0.304, and 0.420, respectively, all of which became significant explanatory variables. From these results, it was confirmed that the thickness of the cortical bone and the voxel values had a positive influence on ITVs, while the thickness of the cortical bone, the voxel value, and the length of the implant had a positive influence on the ISQ values (Table 2).

Table 2 Statistical analysis of the results of the multiple regression analysis of the $3.8-\mathbf{m m}$-width implant

\begin{tabular}{lc} 
Dependent variable $=$ ITVs & $(n=47)$ \\
Independent variables & $\begin{array}{c}\text { Standardized partial regression } \\
\text { coefficient }(P \text { value })\end{array}$ \\
Thickness of the cortical bone & $0.400(=0.02)$ \\
Voxel value & $0.459(<0.01)$ \\
Length of the implant & $0.005(=0.97)$ \\
& $R^{2}=0.633$ \\
Dependent variable = ISQ values & $(n=47)$ \\
Independent variables & Standardized partial regression \\
Thickness of the cortical bone & $0.326(=0.04)$ \\
Voxel value & $0.304(<0.01)$ \\
Length of the implant & $0.420(<0.01)$ \\
& $R^{2}=0.593$ \\
\hline
\end{tabular}

Influence of each factor of the implant of $5.0 \mathrm{~mm}$ in width on ITVs and the ISQ values

The standardized partial regression coefficients of ITVs for the thickness of the cortical bone and the length of the implant were 0.408 and 0.526 , respectively, which became significant explanatory variables. In addition, those of the ISQ values for the thickness of the cortical bone and the length of the implant were 0.440 and 0.750 , respectively, which also became significant explanatory variables. From these results, it was confirmed that the thickness of the cortical bone and the length of the implant had a positive influence on ITVs and the ISQ values. However, the voxel value of ITVs and that of the ISQ values failed to become explanatory variables (Table 3 ).

\section{Discussion}

Measurement of the cortical bone thickness and the voxel values

Ikumi used a MDCT scan for actual patients to calculate the CT values of the $1-\mathrm{mm}$ surrounding area of the planned implant placement site using implant simulation software [25]. However, it is likely that the precise measurement cannot be performed in the case where the actual implant cavity was formed off the planned implant site because the density of the bone around the planned implant site was evaluated by preoperative simulation.

Therefore, we evaluated the bone quality $0.5 \mathrm{~mm}$ surrounding the implant, which was thought to have a strong effect on the primary stabilities, by CBCT scanning after forming the implant cavities. 
Table 3 Statistical analysis of the results of the multiple regression analysis of the $5.0-\mathrm{mm}$-width implant

\begin{tabular}{lc}
\hline Dependent variable $=$ ITVs & $(n=49)$ \\
Independent variables & $\begin{array}{c}\text { Standardized partial regression } \\
\text { coefficient }(P \text { value })\end{array}$ \\
Thickness of the cortical bone & $0.408(=0.04)$ \\
Voxel value & $0.365(=0.10)$ \\
Length of the implant & $0.526(<0.01)$ \\
& $R^{2}=0.638$ \\
Dependent variable $=$ ISQ values & $(n=49)$ \\
Independent variables & Standardized partial regression \\
& coefficient $(P$ value $)$ \\
Thickness of the cortical bone & $0.440(=0.02)$ \\
Voxel value & $-0.060(=0.98)$ \\
Length of the implant & $0.750(<0.01)$ \\
& $R^{2}=0.836$ \\
\hline
\end{tabular}

Nkenke used an axial image to define the thickness of the cortical bone from the average thickness of the cortical bone around the implant measured by eye estimation and then evaluated its relationship with ITVs [26]. Whereas in this study, we measured the thickness of the cortical bone by setting the threshold for the voxel values around the implant for the purpose of securing reproducibility of the measurement of the thickness of the cortical bone. The threshold that we set was determined in the preliminary experiment so that it would highly correlate with the measurement values of the thickness of the cortical bone measured by eye estimation. Conversely, the limitation of this study is that the CBCT device is lacking some precision for estimation of bone density compared to quantitative computed tomography.

\section{Relationship between the thickness of the cortical bone and the voxel values measured by $\mathrm{CBCT}$ and the primary stability of the implant}

To date, there are several studies that investigated the relationship between the thickness of the cortical bone and the primary stability of the implant. Motoyoshi placed a total of 87 mini-implants, which were used as anchors for orthodontic treatment, in the buccal alveolar bone in the molar region of actual patients [27]. As a result, they reported that they found a positive significant correlation between the thickness of the cortical bone measured by using medical CT images and the torque value at the time of placement. Roze measured the thickness of the cortical bone of the jawbones in three human bodies using $\mu \mathrm{CT}$ and placed a total of 22 implants [28]. According to this report, there was a significant correlation between the thickness of the cortical bone and the ISQ values measured immediately after the implant placement. Furthermore, Isoda reported a significant correlation between the bone quality around the implants and the implant stabilities.

Although this study is different from the previous studies in that the thickness of the cortical bone and bone density were determined from the voxel values calculated by CBCT, a significantly positive correlation of the thickness of the cortical bone and the voxel values with ITVs and ISQ values was confirmed as in the previous studies. Furthermore, the multiple regression analysis with the ITVs and the ISQ values as the dependent variables showed that the thickness of the cortical bone as well as the voxel values had a positive influence.

Based on these results, it was revealed that the thickness of the cortical bone obtained from CBCT had a correlation with the ITVs and the ISQ values which are the indexes of the primary stability of the implant. It was also revealed that the voxel values correlated with ITVs and ISQ values. It is desirable to be able to infer the primary stability at the time of implant placement not only from the thickness of the cortical bone but also from the voxel values, if the cortical bone cannot be observed on the CT images of the extraction socket immediately after or at a certain period of time after the tooth extraction (until the maturation of the bone). Conversely, there was no statistical correlation between the voxel values and ISQ values among 5-mm-diameter, 12-mm-length implants. These ISQ values were high enough regardless of bone densities, and this caused that the correlation did not confirm between voxel values and ISQ values.

In addition, these results were confirmed by using mechanically polished surface implants. Therefore, it is thought that primary stability becomes more stable by using rough-surface implants.

\section{Conclusions}

In this limited study, there was a correlation between the thickness of the cortical bone or the voxel values obtained from the CBCT scanning images prior to the implant placement and the implant stabilities. Besides, it was confirmed that the thickness of the cortical bone, the voxel value, and the length of the implant had positive correlations with the ITVs and that the thickness and length had positive correlations with the ISQ values.

\section{Competing interests}

Masahiro Wada, Yasutane Tsuiki, Tohru Suganami, Kazunori Ikebe, Motofumi Sogo, Ikuhisa Okuno and Yoshinobu Maeda declare that they have no competing interests.

\section{Authors' contributions}

MW drafted the article and collected the data. YT and TS collected the data. $\mathrm{KI}$ performed the data analysis and statistical analysis. MS interpreted the data. $\mathrm{IO}$ analyzed the data. YM designed the research and approved the article. All authors read and approved the final manuscript.

Acknowledgements

This study was partially supported by GC Company. 
Received: 18 September 2014 Accepted: 20 November 2014 Published online: 12 February 2015

\section{References}

1. Ottoni JM, Oliveira ZF, Mansini R, Cabral AM. Correlation between placement torque and survival of single-tooth implants. Int J Oral Maxillofac Implants. 2005; 20:769-76.

2. Beer A, Gahleitner A, Holm A, Tschabitscher M, Homolka P. Correlation of insertion torques with bone mineral density from dental quantitative $\mathrm{CT}$ in the mandible. Clin Oral Implants Res. 2003; 14(5):616-20.

3. Meredith N. Assessment of implant stability as a prognostic determinant. Int J Prosthodont. 1998; 11(5):491-501.

4. Martinez H1, Davarpanah M, Missika P, Celletti R, Lazzara R. Optimal implant stabilization in low density bone. Clin Oral Implants Res. 2001; 12(5):423-32.

5. Lioubavina-Hack N, Lang NP, Karring T. Significance of primary stability for osseointegration of dental implants. Clin Oral Implants Res. 2006; 17(3):244-50.

6. Molly L. Bone density and primary stability in implant therapy. Clin Oral Implants Res. 2006; 17(Suppl 2):124-35.

7. Orenstein $\mathrm{H}$, Tarnow DP, Morris HF. Three-year post-placement survival of implants mobile at placement. Ann Periodontol. 2000; 5:32-41.

8. Turkyilmaz I, Company AM. Sensitivity of resonance frequency analysis method to assess implant stability. NY State Dent J. 2011; 77(5):44-9.

9. Su YY, Wilmes B, Hönscheid R, Drescher D. Application of a wireless resonance frequency transducer to assess primary stability of orthodontic mini-implants. An in vitro study in pig ilia. Int J Oral Maxillofac Implants. 2009; 24(4):647-54.

10. Ohta K, Takechi M, Minami M, Shigeishi H, Hiraoka M, Nishimura M, Kamata N. Influence of factors related to implant stability detected by wireless resonance frequency analysis device. J Oral Rehabil. 2010; 37(2):131-7.

11. Turkyilmaz I. A comparison between insertion torque and resonance frequency in the assessment of torque capacity and primary stability of Brånemark system implants. J Oral Rehabil. 2006; 33(10):754-59.

12. Herrmann I, Lekholm U, Holm S, Kultje C. Evaluation of patient and implant characteristics as potential prognostic factors for oral implant failures. Int J Oral Maxillofac Implants. 2005; 20:220-30.

13. Jaffin RA, Berman CL. The excessive loss of Branemark fixtures in type IV bone: a 5-year analysis. J Periodontol. 1991; 62:2-4.

14. Lekholm U, Zarb G. Patient selection and preparation. In: Osseointegration in Clinical Dentistry. Chicago: Quintessence Publishing Co, Inc. 1985; p. 199-209

15. Misch CE. Contemporary Implant Dentistry. St. Louis: Mosby, 1993; p. 469-85.

16. Turkyilmaz I, Sennerby L, McGlumphy EA, Tozum TF. Biomechanical aspects of primary implant stability: a human cadaver study. Clin Implant Dent Relat Res. 2009; 11:113-9.

17. Kobayashi K, Shimoda S, Nakagawa Y, Yamamoto A. Accuracy in measurement of distance using limited cone-beam computerized tomography. Int J Oral Maxillofac Implants. 2004; 19:228-31.

18. Loubele M, Maes F, Schutyser F, Marchal G, Jacobs R, Suetens P. Assessment of bone segmentation quality of cone-beam CT versus multislice spiral CT: a pilot study. Oral Surg Oral Med Oral Pathol Oral Radiol Endod. 2006; 102:225-34.

19. Schulze D, Heiland M, Thurmann H, Adam G. Radiation exposure during midfacial imaging using 4- and 16-slice computed tomography, cone beam computed tomography systems and conventional radiography. Dentomaxillofac Radiol. 2004; 33:83-8.

20. De Vos W, Casselman J, Swennen GR. Cone-beam computerized tomography (CBCT) imaging of the oral and maxillofacial region: a systematic review of the literature. Int J Oral Maxillofac Surg. 2009; 38:609-25.

21. Kl H, Kawashima S, Araki M, Iwai K, Sawada K, Akiyama Y. Comparison of image performance between cone-beam computed tomography for dental use and four-row multidetector helical CT. J Oral Sci. 2006; 48(1):27-34.

22. Araki K, Okano T. The effect of surrounding conditions on pixel value of cone beam computed tomography. Clin Oral Implants Res. 2013; 24(8):862-5.

23. Eskandarloo A, Abdinian M, Salemi F, Hashemzadeh Z, Safaei M. Effect of object location on the density measurement in cone beam computed tomography versus multislice computed tomography. Dent Res $J$ (Isfahan). 2012; 9(Suppl 1):S81-7.
24. Nackaerts O, Maes F, Yan H, Couto Souza P, Pauwels R, Jacobs R. Analysis of intensity variability in multislice and cone beam computed tomography. Clin Oral Implants Res. 2011; 22(8):873-9.

25. Ikumi N, Tsutsumi S. Assessment of correlation between computerized tomography values of the bone and cutting torque values at implant placement: a clinical study. Int J Oral Maxillofac Implants. 2005; 20:253-60

26. Nkenke E, Hahn M, Weinzierl K, Radespiel-Troger M, Neukam FW, Engelke K. Implant stability and histomorphometry: a correlation study in human cadavers using stepped cylinder implants. Clin Oral Implants Res. 2003; 14:601-9.

27. Motoyoshi M, Yoshida T, Ono A, Shimizu N. Effect of cortical bone thickness and implant placement torque on stability of orthodontic mini-implants. Int J Oral Maxillofac Implants. 2007; 22:779-84.

28. Roze J, Babu S, Saffarzadeh A, Gayet-Delacroix M, Hoomaert A, Layrolle P. Correlating implants stability to bone structure. Clin Oral Implants Res. 2009; 20:1140-45.

\section{Submit your manuscript to a SpringerOpen ${ }^{\circ}$ journal and benefit from:}

- Convenient online submission

Rigorous peer review

- Immediate publication on acceptance

- Open access: articles freely available online

- High visibility within the field

- Retaining the copyright to your article

Submit your next manuscript at $>$ springeropen.com 